that the centres treated thousands of displaced and traumatized people.

Some residents reported watching corpses float by as they waited to escape their flooded homes. Families were separated as emergency responders herded people into temporary holding centres, and police wielding guns prevented newly homeless people from crossing a bridge to escape the city. "There were so many ways in which common humanity was shut down by dystopian images and rumours," says Jean Rhodes, a clinical psychologist at the University of Massachusetts in Boston.

At least one study of storm-ravaged areas in Alabama, Louisiana and Mississippi suggests that mental-health conditions, such as posttraumatic stress disorder (PTSD) and depression, worsened over time ${ }^{1}$. The prevalence of PTSD in these regions rose from $15 \%$ a few months after the storm to $21 \%$ one year later, and the proportion of people experiencing suicidal thoughts more than doubled from $2.8 \%$ to $6.4 \%$. Robert Ursano, a psychiatrist at the Uniformed Services University in Bethesda, Maryland, says that this reflects the difficulties that survivors faced when trying to cope with loss or meet basic needs, such as finding housing.

"There was a level of uncertainty about whether or not recovery would be possible that I don't think has been encountered before in the United States," says Elizabeth Fussell, a demographer who was working at Tulane University in New Orleans when the storm hit.

Rhodes argues that simple steps might have mitigated the mental-health toll. Studies reveal that people who had strong social-support networks when Katrina hit were more resilient to psychological trauma ${ }^{2}$. Yet in many cases, officials' actions severed such ties; many residents of flooded, poor areas were sent by bus to randomly assigned US cities, for example. Sorting evacuees into shelters by neighbourhood could be one way to prevent this stress, says Rhodes.

Rhodes has a rare perspective on the factors that influenced mental and physical health following the storm. In 2003, she and her colleagues had begun to study whether giving college scholarships to a group of 1,019 lowincome New Orleans parents would increase their well-being. Katrina halted this work, but the researchers were able to use the alreadycollected medical and demographic data to track changes in health caused by the hurricane. Such baseline data are rare in disaster research, and are especially valuable for studying poor communities, which tend to have high rates of stress and mental illness.

The renamed, refocused Resilience in
Survivors of Katrina (RISK) Project still follows many of the original study participants. Nearly half of the 392 low-income parents participating in the revised project had symptoms of PTSD one year after the hurricane, and the rate of other serious mental illnesses such as depression and psychosis doubled to 14\% (ref. 3).

But these storm survivors ultimately displayed resilience. About one-third reported 'post-traumatic growth': the feeling that surviving the disaster made them stronger, even if they simultaneously experienced from mental illness. Three years after the storm, the RISK team found that two-thirds of the 386 African American women who participated in the original study no longer displayed the signs of psychological distress that were evident just after Katrina hit ${ }^{4}$.

"People kind of see disasters on TV and say, 'How are these people ever going to build their lives again?"' Rhodes says. "We see that the vast majority of people over time bounce back." -

1. Kessler, R. C. et al. Mol. Psychiatry 13, 374-384 (2008).

2. Chan, C. S., Lowe, S. R., Weber, S. R. \& Rhodes, J. E. Soc. Sci. Med. 138, 38-43 (2015).

3. Rhodes, J. et al. Am. J. Orthopsychiatry 80, 237-247 (2010).

4. Lowe, S. R. \& Rhodes, J. E. Am. J. Orthopsychiatry 83, 398-412 (2013).

\title{
North Pacific 'blob' stirs up fisheries management
}

\section{Unusual warmth strengthens calls for ecosystem-based decisions.}

\section{BY VIRGINIA GEWIN}

$\mathrm{U}$ nprecedented conditions in the Pacific Ocean have sent fisheries managers into uncharted waters. 'The blob', an unusually warm mass of water that has been parked in the northern Pacific for 18 months, has quelled upwelling that delivers nutrients to coastal waters where migratory salmon, tuna and whales fatten themselves on 'forage species' such as anchovies, sardines and krill.

The nutrient shortage comes at a time when populations of many of those forage species are already at historic lows. With a strengthening El Niño - warmth in the eastern equatorial Pacific that affects weather patterns worldwide - fisheries managers face a good deal more uncertainty than usual as they prepare to set catch limits for next year.

The situation lays bare the need to consider ecological processes in fisheries decisionmaking, scientists said at the American
Fisheries Society annual meeting in Portland, Oregon, last week. Managers tend to base limits on assessments that focus on individual species and presume that population trends are stable. Ecosystem-based fisheries management aims for a more comprehensive approach that considers variables such as predatorprey relationships, climate conditions and economic factors.

Up to now, the bodies that set catch limits have used ecosystem-based approaches only sparingly. But last November, the Pacific Fishery Management Council, which makes catch recommendations for the West Coast to the US National Marine Fisheries Service, reviewed and conditionally endorsed a comprehensive ecosystem-based computer model - the first step towards bringing such a tool into management decision-making.

"Uptake of these principles has been relatively slow," says Tim Essington, a fisheries scientist at the University of Washington in Seattle.
The biggest barrier may be the need to collect and analyse relevant biological data, such as information on how fluctuations in the population of a prey species will affect its predators. Supporters of ecosystem-based fisheries are creating tools such as the California Current Predator Diet Database, which is amassing information about the eating habits of 119 species. At the fisheries meeting, Amber Szoboszlai, a research analyst at the Farallon Institute for Advanced Ecosystem Research in Petaluma, California, showed how she had used the database to determine that fish eat $75 \%$ of the anchovies consumed in the Pacific, whereas mammals eat only $16 \%$ and seabirds $7 \%$.

If the blob signals a regime change in the Pacific, conservationists argue that ecosystem-based management will be essential to preventing a catastrophe. "The whole system seems to be changing radically," says Rebecca Goldburg, director of ocean science for the Pew Charitable Trusts in Washington DC. 